\title{
Narrativa do Teko Porã na poesia de Brígido Bogado $^{1}$
}

\section{The narrative of Teko Porã in the poetry of Brígido Bogado}

\section{Ligia Karina Martins de Andrade*}

\begin{abstract}
Resumo: Este estudo analisa a representação do Teko Porã na poesia de Brígido Bogado a partir da perspectiva dos estudos ecocríticos. Tal representação aponta a cosmovisão indígena a partir da língua e dos saberes ancestrais que se apresentam subjacentes à obra do autor e denunciam uma crítica às formas de depredação da natureza levadas adiante pela sociedade do Capital e da alienação das relações humanas que se impõem desde a colonização do espaço, dos corpos e das mentes na América, como apontado por Aníbal Quijano (2000). O artigo de Meliá (2015) "El buen vivir se aprende" aborda a complexidade do termo Teko Porã na cultura dos guaranis. Observa-se ainda uma possibilidade de se repensar os estudos ecocríticos desde uma perspectiva latino-americana, o que, de acordo com Flores (2017), pode revelar outras formas de saberes e relações entre os seres humanos e a natureza, as quais prescindem das formas de domínio estabelecidas pelos grupos hegemônicos do Ocidente até os dias atuais.
\end{abstract}

Palavras-chave: Teko Porã. Brígido Bogado. Ecocrítica.

\begin{abstract}
This study analyzes the representation of Teko Porã in the poetry of Brígido Bogado from the perspective of ecocritical studies. Such representation indicates the indigenous cosmovision based on the ancestral language and knowledge that are presented underlying the work of the author and exposes the criticism of the depredation of nature carried forward by the society of capital and the alienation of human relations that have been imposed since the colonization of the area, bodies and minds in America, as pointed out by Aníbal Quijano (2000). The article by Meliá (2015) "El buen vivir se aprende" addresses the complexity of this term the Teko Porã in Guarani's culture. It is further observed the possibility to rethink ecocritical studies from a Latin
\end{abstract}

\footnotetext{
${ }^{1}$ Uma versão preliminar deste texto foi apresentada no "II SEMINÁRIO INTERNACIONAL DE PÓS-GRADUAÇÃO EM DESENVOLVIMENTO RURAL SUSTENTÁVEL” em Foz do Iguaçu, entre 07 a 09 de agosto de 2019, sendo indicado pelo evento para compor este volume especial.

* Doutora em Letras - Língua Espanhola pela Universidade de São Paulo (USP); Mestre em Letras - Língua Espanhola pela USP; Professora de Língua Espanhola Adicional na Universidade Federal da Integração Latino-Americana (UNILA). E-mail: ligia.andrade@unila.edu.br.
} 
American perspective, according to Flores (2017), which reveals other ways of knowing and another relationship between humans and nature that dispenses the means of dominance established by Western hegemonic groups to the present day.

Keywords: Teko Porã. Brígido Bogado. Ecocritical Studies.

Recebido em 12/11/2019. Aceito em 11/03/2020.

\section{Introdução}

Este artigo trata de analisar a cosmovisão do povo Mbya Guarani a partir da leitura da obra Ayvu i (2009) e Cantos de la tierra: Reflexiones poéticas de un Mbya Guaraní (2014) de Brígido Bogado. A poesia do autor contém uma série de elementos que resgatam a relação deste povo com a terra e o sentido da vida que serão analisados sob a perspectiva dos estudos ecocríticos. A representação do conceito de Teko Porã será comparada à perspectiva filosófica e ética que se aproxima do "buen vivir", traçado pelo crítico Meliá (2015), com o objetivo de avaliarmos as implicações e os sentidos deste conceito-chave para o povo guarani em geral e com respostas políticas e estéticas na poesia do autor. Além disto, partirmos de uma concepção de descolonização do saber e poder de Quijano (2000) e Flores (2017) e, no caso do último autor, este reivindica uma "perspectiva dialógica autóctone" no contexto ecocrítico latino-americano, a partir de uma relação material e espiritual do indígena com o espaço e a natureza.

\section{A ecocrítica e o Teko Porã}

Para levar adiante esta análise, partiremos da reflexão de alguns textos jornalísticos sobre o povo guarani na atualidade e observaremos o discurso da narrativa secular, desencantada e espetacular que é utilizado para se referir às questões da territorialidade. Em seguida, analisaremos o conceito de Teko Porã na língua guarani e sua gama de significados e possibilidades de tradução a partir do artigo de Meliá "El buen vivir se aprende" (2015) em relação aos poemas do Mbya Guarani Brígido Bogado. Logo, passaremos a analisar as possibilidades de tradução deste conceito e do leque semântico que algumas palavras abrangem em guarani e que correspondem a certa visão de mundo e saberes que atingem alcances significativos na obra do autor.

O povo guarani utiliza uma frase emblemática para iniciar a compreensão de sua cosmovisão, que diz o seguinte: "Sem Tekoha não tem Tekovy'a", no qual o primeiro termo pode ser traduzido por "terra sagrada" e o segundo por "vida feliz" (RODAS; BENÍTEZ, 2018). O crítico Meliá, traduz por "buen vivir" em espanhol, ou "bem viver" em português (tradução nossa), a expressão tekoha e, em seu estudo, ele demonstra a complexidade de utilizar um termo equivalente para condensar a cosmovisão e a realidade vivida e sentida pelos guaranis ao falar de sua terra e da relação vital que estabelecem com a mesma. A dimensão sagrada da terra alia-se à concepção de pertencimento, pois o contexto indígena parte da noção de habitar um território num sentido pleno, o qual nasce de sua criação cultural e social e, ainda, está relacionado diretamente ao ser ou à existência do ser, pois sem um não existe o outro. Neste sentido, a terra não pode ser ocupada ou invadida por 
meio de uma relação coisificada e desencantada. Este sentido sagrado que advém da terra, como explica Meliá, contrasta, muitas vezes, com a concepção desde o período colonial em que esta estava para ser distribuída aos grupos dominantes com o intuito de criar propriedades privadas para exploração e lucro até sua extinção como recurso natural nos dias atuais.

Há um fato na contemporaneidade que revela a contradição das políticas de Estado e que está exemplificado na reportagem de 19 de abril de 2018 "Guaranis vivem sob tensão no Oeste", publicada pelo jornal H2FOZ (PARO, 2018), que retrata a situação dos guaranis que vivem próximo à Usina Hidrelétrica de Itaipu, os quais na época de construção da usina foram desalojados de suas terras ancestrais, que hoje estão sob as águas. A jornalista Denise Paro aponta, nesta reportagem, que o povo guarani reivindica a importância de se retomar parte das terras que estão atualmente sob o controle da empresa, devido a uma série de violações históricas ao longo do processo de construção do megaprojeto binacional (Brasil e Paraguai).

Além de todas as violações apontadas pela reportagem no processo de retirada deste povo de seu lugar ancestral, temos ainda a característica nômade de ocupação das terras pelos mesmos, o que explica a saída e o retorno dos territórios por eles ocupados em algum momento de sua história. Estes elementos alinham-se no texto da reportagem, ocupando um importante espaço no jornal. No entanto, o episódio que marca o critério de noticiabilidade é a acusação de que alguns indígenas estavam extraindo bambu da floresta, o que é considerado crime ambiental. Após uma série de mostras de discriminação e intolerância revelados no discurso da imprensa e nas falas de autoridades, os indígenas foram obrigados a pagar uma fiança para serem libertados da prisão. Além disto, o título da reportagem "Guaranis vivem sob tensão no Oeste" possui uma linguagem de alarme e polêmica típica de uma parcela do discurso jornalístico atual. É evidente também que o apontado nomadismo da Nação guarani em busca da Yvy Marãe'y (Terra sem mal) foi profundamente alterado pela expropriação e exploração a que estes povos foram submetidos desde a Colônia. Estes elementos foram considerados na reportagem de Denise Paro (2018), mas de forma lacônica, talvez numa referência ao fato de voltarem ao antigo território, agora sob posse de Itaipu.

Este episódio revela a contradição dentro das políticas de Estado com relação aos povos originários e ao desconhecimento de sua cultura e noção de território, confrontando diretamente uma visão encantada e de uso coletivo do espaço a uma visão de propriedade privada que visa o uso dos recursos naturais para obter posse ou reserva de capital. Além disto, o centro do debate gira em torno de uma concepção indígena divergente da nacional, de acordo com Flores:

Parte de este discurso indígena es una crítica al uso del discurso ecologista como pretexto para la expropiación de sus tierras y la destrucción de su sistema de vida. Este discurso indígena difiere del discurso ecologista dominante en que reclama que se conozca al indígena como ser humano indesplazable del espacio en que habita. Este discurso rechaza la desterritorialización cultural y geográfica de indígenas y la preservación de los espacios naturales por poderes administrativos no locales (FLORES, 2017, p. 44)².

\footnotetext{
2 "Parte deste discurso indígena é uma crítica ao uso do discurso ecologista como pretexto para a expropriação de suas terras e a destruição de seu sistema de vida. Este discurso indígena difere do discurso ecologista dominante em que reivindica que se reconheça o indígena como ser humano não destituível do espaço em que mora. Este discurso rejeita a desterritorialização cultural e geográfica de indígenas e a preservação dos espaços naturais por poderes administrativos não locais." (FLORES, 2017, p. 44, tradução nossa).
} 
Não se trata como avalia o crítico peruano de reivindicar a estes povos a figura do "bom selvagem nativo" que preserva e defende a natureza, porque incorreríamos na análise das teorias ecologistas da década de setenta, do século XX, que seguem a corrente do discurso hegemônico preservacionista. Neste sentido, Flores (2017, p. 43) aponta a obra de Devall e Session que denominam estas sociedades de "ecosystem people", desenvolvendo as bases para o indígena como "nobre selvagem ecológico", termo que funda parte dos princípios da ecologia moderna. Esta mesma retórica é a que transforma as reservas indígenas em centros de turismo com o intuito de preservar e, ao mesmo tempo, tornar estas comunidades sustentáveis por meio do uso da paisagem e da promoção de um contato com a natureza para aqueles que vivem, sobretudo, nos centros urbanos. Tal discurso transforma ainda os territórios indígenas em áreas de preservação ambiental, muitas vezes excluindo os seres humanos. Neste sentido, a situação dos territórios torna-se ainda mais complexa, pois a área ao redor da usina de Itaipu é considerada como Área de Preservação Ambiental (APA), estando sob fiscalização da lei e sua legislação ambiental.

Flores (2017) aponta, em sentido contrário a estes discursos apropriados pelos grupos hegemônicos de preservação, a reivindicação de que estes povos podem constituir um discurso ecocrítico autóctone latino-americano que boicotaria este discurso conservacionista hegemônico e oficial apontado neste estudo. Esta perspectiva relacionada aos antepassados e à relação encantada e espiritual com o espaço, ou seja, em que cultura e natureza estão alinhadas e integradas, podem responder às indagações atuais sobre conflitos territoriais e reparar as desigualdades históricas da região. Flores desenvolve uma perspectiva que vai além de uma ecocrítica enquanto disciplina, sobretudo as vertentes desenvolvidas nos Estados Unidos e Inglaterra, e que, a partir da década de setenta, esboça a ecocrítica como fruto de certa consciência ecológica e que conecta a natureza e a cultura e tenta mostrar "(...) a materialidad de las interrelaciones e integraciones de los soportes y elementos que aseguran la vida básica del planeta” (OSTRÍA GONZÁLEZ, 2008, p. 222, apud FLORES, 2017, p. 43) ${ }^{3}$.

A obra de Quijano (2000) explicita como se deu a colonialidade dos saberes, corpos, mentes e recursos que serviu ao projeto de domínio dos grupos hegemônicos, para os quais todos os seres estavam subjugados aos interesses do lucro e da propriedade privada, desconsiderando qualquer outra subjetividade e formas de organização política e filosófica de relação entre os seres humanos e os não humanos. Observaremos de que modo a poesia de Bogado revela uma possibilidade de descolonização do pensamento.

\section{A poesia de Brígido Bogado: língua e saberes indígenas}

Em contraste com esta visão anteriormente desenvolvida de terra como propriedade no sistema colonialista e, também, dos recursos naturais como fonte de riquezas, analisaremos a obra de Brígido Bogado e a cosmovisão do coletivo Mbya Guarani do qual ele faz parte. O poeta atualiza por meio da voz, poesia e universo representados a voz do coletivo, o que torna sua produção de inestimável valor artístico e cultural para a humanidade.

Brígido nasceu próximo de "Colonia Fram" (Paraguai), em 1963, e foi adotado por uma família não indígena. Cursou estudos de Teologia e Filosofia na "Universidad Católica de Asunción" e, após anos de separação, regressa a uma comunidade Mbya Guarani. Atualmente, é docente aposentado e está cursando Licenciatura em Ciências da Comunicação. É autor de vários livros e

3 “(...) a materialidade das interrelações e integrações dos suportes e elementos que garantem a vida básica no planeta" (OSTRIA GONZÁLEZ, 2008, p. 222 apud FLORES, 2017, p. 43, tradução nossa). 
considerado pela crítica o "primeiro poeta indígena paraguaio" (ALTAMIRANO, 2019, p. 1), sendo ainda um importante difusor e fomentador da cultura e língua dos Mbyas no Paraguai.

O poeta resgata, por meio de uma estética inovadora, que também possui um sentido político, o canto e a dança da criação do mundo pelo Deus Ñanderú, de modo que a propriedade da terra perde o sentido e ganha espaço a vivência que o locus do "bem viver" proporciona, porque, ao mesmo tempo, é vivenciado e cultuado. Neste contexto, o tekoha ou teko porã é evocado pelo poeta em sua tradição cantada e dançada. A tradução ao espanhol - e também se estendemos a tradução ao português - perde este sentido, porque não pode resgatar a relação de harmonia e equilíbrio dos povos nativos, segundo os quais cada elemento da natureza faz parte de um todo e que a Mãe Terra é a responsável pela criação, devendo ser cuidada, e não apenas "preservada" como um recurso, de acordo com o discurso conservador ecologista. A diferença da cosmovisão indígena em guarani se faz notar na falta de termos equivalentes em espanhol na obra Ayvu $i$ de Bogado (2009), daí termos as seguintes traduções do guarani ao castelhano ou de auto tradução, de acordo com o contexto de aparição nos poemas: por exemplo "teko" é traduzido por "natura" (p. 8), "tierra", “amor" (p. 17), "vida" (p. 17); "tekoha” é traduzido por "tierra" e "teko porã" se traduz como “oración” (p. 14), “vida equilibrada”, "vida feliz” (p. 21), “el principio vida” (p. 25), "vida" (p. 31) e ainda "tekoasy" aparece traduzido como "humanidad" (p. 10) e "ser humano" (p. 10). Na auto tradução, há muitas estratégias do traduzir, mas destacamos a coincidência entre a voz do poeta e a voz do tradutor no verso produzido (PEÑALVER, 2011, p. 195), pois Bogado escreve em guarani e ele próprio traduz seus poemas ao castelhano na obra Ayvu i (2009).

De acordo com Meliá (2015), é por meio da língua guarani que se dá o atrelar da constituição do indivíduo como sujeito cultural e político aos saberes ancestrais que lhe são transmitidos através das gerações. Estes ensinamentos ocorrem por meio da palavra (poética, narrada, cantada, etc.) que é sagrada e também cumpre um movimento ancestral ligando as gerações no tempo e no espaço. Por isto, o território é uma construção cultural e uma identificação direta do sujeito com sua cultura. A referência ao criador Ñanderú está presente no texto de modo poético e profético, uma vez que há referência a sua figura como aquele que surge das trevas primitivas sentado em um "apyka" e desde aí ele "se abre como flor". O território para os guaranis é uma criação de sua cultura, devido a isto não pode ser ocupado ou conquistado, mas sim pensado e vivido. Esta perspectiva está compreendida na cosmovisão guarani por meio de cinco palavras que estão relacionadas ao território:

El territorio guaraní, que en realidad es un espacio cultural, se puede representar em cinco palabras, que concatenadas significan el buen vivir: apyka, ava pire, teko, tehoha, teko porã. El camino hacia este espacio, que lo predice y lo expresa, es el ñée -la palabra- y el ñembo'e-hacerse palabra (MELIÁ, 2015, p. 1).

Neste sentido, Ñanderú toma do "apyka”, que é o lugar de criação e eclosão da vida, este instante para transmitir a palavra divina, que depois cada ser vai tomar para si como o sopro vital e continuar a rede de significação em guarani. É interessante porque o mito criador revela o "apyka" como o lugar onde também o sentido "se abre em flor", numa referência à natureza e ao início da vida vegetal. Meliá $(2015$, p. 1) adverte sobre o sentido profundo de apyka: “(...) es

\footnotetext{
4 "O território guarani, que na verdade é um espaço cultural, pode-se representar em cinco palavras, que concatenadas significam o bem viver: apyka, ava pire, teko, tehoha, teko porã. o caminho até este espaço, que o prediz e o expressa, é o $\tilde{n} e^{\prime} e$-a palavra- e o ñembo'e-fazer-se palavra." (MELIÁ, 2015, p. 1, tradução nossa).
} 
el primer territorio o cultura-torio, y éste es el seno de la madre, el lugar donde se sienta y se asienta la primera y única palabra de la persona, que se hace carne y habita entre nosotros"5.

Vejamos alguns fragmentos da obra de Brígido Bogado. O poema "Tierra sin mal" (Yvy marae'y), em Ayvu i, tráz estes versos que ilustram a concepção de "asiento de la vida" ou lugar sagrado e de morte: "Vacio quedó el asiento de la vida/ soplo de vida que viene y va/ El padre Tupã bajó en la tierra/ a llevar a las almas al infinito" (BOGADO, 2009, p. 28)6. Os versos em guarani aparecem da seguinte forma: “Tekoha opyta nandi/ yvytu oho há ou/ Nande Ru Tupã oguata/ ñe'ê kuéry ogueraha” (BOGADO, 2009, p. 28). Isto é interessante na medida em que a palavra é o elemento que humaniza e torna os guaranis uma única Nação, apesar de constituírem vários povos, pois o ser cultural e o estar num território sociocultural, está mediado pela pele ("ava pire") que envolve e também se apresenta, mas não sem o sopro, sem a voz, e daí o cantar e o dançar como fundamentos. O corpo e sua aprendizagem cultural estão presentes no contexto indígena, e é o que os diferencia dos outros seres vivos, mas como já mencionamos, não os hierarquiza frente aos outros seres. A pele também pode ser a pele da escrita, o livro, que na superfície pode dizer coisas, pois a palavra é o seio da mãe, é a origem e é o destino do ser guarani ao se relacionar com o mundo.

No poema “Quién eres tú Mbya Guaraní” da obra Cantos de la tierra (2014), observamos esta relação nos seguintes versos: "Sólo puede conocerte/ el que tiene tu misma esencia/ en cuya simplicidad/ tu Palabra-Alma/ en el soplo divino/ que custodia la natura" (BOGADO, 2014, p. $13)^{7}$. E mais adiante, temos uma referência aos males da vida: "Si tu cuerpo sufriera, /las calamidades del tekoasy, /Ñande Rú te ha de levantar, /solo por la fuerza de tu jerovia, /sin los otros tratamientos." (BOGADO, 2014, p. 13) ${ }^{8}$.

Nestes versos analisados são recorrentes a referência ao "tekoasy”, "tekohá”, "tekó porã”, etc., como elementos que tratam esta relação dos Mbyas com o território que é cultura, lugar de florescimento da vida, da língua e do ser humano. A "jerovia" representa a "fé" ou a "esperança" nestes elementos mencionados anteriormente e na palavra divina de Ñanderú. O desequilíbrio gerado pela sociedade de consumo, que trata a natureza de forma a fornecer recursos que são exauridos, sem um uso coletivo e relacional, entra em choque com a cosmovisão dos povos indígenas de toda a Abya Yala. Na poesia de Douglas Diegues, um autor fronteiriço que criou a estética do portunhol selvagem e parodia a mistura de tradições e o domínio da civilização do Capital em decadência, temos de acordo com sua definição o seguinte:

(...) El portunhol selvagem brota de la nada como flor selvagem de la buesta de las vakas." (...) Ou seja: non soy nim fui el inventor del portunhol selvagem. Soy apenas el inbentor de um concepto de portunhol selvagem, um portunhol salbahem enquanto habla y escritura y non-lengua. (DIEGUES, 2009, p.1) .

\footnotetext{
5 “(...) é o primeiro território ou cultura-tório, e este é o seio da mãe, o lugar onde se senta e se assenta a primeira e única palavra da pessoa, que se faz carne e habita entre nós” (MELIÁ, 2015, p. 1, tradução nossa).

6 "Vazio ficou o assento da vida/ sopro de vida que vem e vai/ o pai Tupã baixou na terra/ a levar as almas ao infinito" (BOGADO, 2009, p. 28, tradução nossa).

7 "Só pode conhecer-te/ aquele que tem tua mesma essência/ em cuja simplicidade/ tua Palavra-Alma/ no sopro divino/ que custodia a natureza" (BOGADO, 2014, p. 13, tradução nossa).

8 "Se teu corpo sofresse,/ as calamidades do tekoasy, /Ñande Rú te vai levantar, /só pela força de tua jerovia,/sem os outros tratamentos" (BOGADO, 2014, p. 13, tradução nossa).

9 “(...) O portunhol selvagem brota do nada como flor selvagem da bosta das vacas." (...) Ou seja: não sou nem fui o inventor do portunhol selvagem. Sou apenas o inventor de um conceito de portunhol selvagem, um portunhol selvagem enquanto fala e escrita e não-língua" (DIEGUES, 2009, p. 1, tradução nossa).
} 
A partir da escrita em portunhol selvagem que nasce como "flor selvagem da bosta das vacas" (tradução nossa), é possível contrastar a visão paródica e desencantada de Douglas Diegues à concepção mítica evocada por Brígido Bogado, pois temos dois autores que ingressam por tendências literárias e estéticas diversas para tratar a palavra e suas potencialidades. No caso de Douglas Diegues, profundo conhecedor da cultura guarani e criador do "portunhol salbaje", a dimensão crítica e paródica predomina, ao passo que Brígido Bogado se deixa mergulhar na espiritualidade de seu povo para escrever nesta variante Mbya do guarani e ser denominado como o "primeiro poeta indígena" (ALTAMIRANO, 2019, p. 1), pois o conceito ocidental de literatura ou de autoria não pertencia aos povos indígenas. Após o contato, vemos surgir nestas coletividades destacados narradores e poetas, como a cultura letrada do Ocidente denomina, mas a herança cultural e o conhecimento são transmitidos e preservados entre as gerações. A obra de Bogado dialoga ainda com o texto sagrado “Ayvu Rapyta. Textos míticos de los Mbyá Guaranídel Guairá" (1959), recopilados por León Cadogan, e que constitui uma das principais fontes escritas de conhecimento dos mitos deste povo. Consideramos que o autor parte de uma narrativa consagrada do povo Mbya, mas a partir de uma posição desafiadora tanto como poeta, ao escrever novos versos, quanto como voz coletiva de uma tradição, daí a auto tradução ao castelhano da obra "Ayvu i", que só poderia ser escrita em guarani, mas sem desconsiderar que parte do leitor não domina esta língua.

No poema de Bogado "La agonía de la tierra", na obra Cantos de la tierra (2014), a denúncia de agressão do solo pela sociedade secular aponta um futuro agonizante, ao que o poeta reivindica a solução por meio da volta do filho ao "caminho natural": "La inerte vida de la tierra/ va cubriéndose de tiempo/y las arrugas van/ curtiendo su piel/ con un sin fin de grietas/ invisibles." (BOGADO, 2014, p. 42) ${ }^{10}$. Ele aponta o conflito entre os grupos na sociedade e o resultado da destruição do planeta: "Hoy tus hijos legítimos,/ ya están muriendo contigo,/ y son tus otros hijos,/ los que van dejando la/ herencia de un triste/ destino." (BOGADO, 2014, p. 42) ${ }^{11}$. E, ao final, o poema prenuncia o possível colapso da humanidade caso não sejam revistas a ocupação dos espaços e a busca por soluções menos depredatórias:

En cada espacio de aire no-puro/es la humanidad que agoniza,/es ella misma en el/suicidio,/que se va negando la vida./Agoniza la tierra,/agoniza inerte,/ pero es ella la vida/y más tiempo se agrietan/sus heridas./ Tal vez el hijo/ se detenga a pensar,/y a la madre agonizante,/ se vuelva a recuperar,/pero solo el hijo/vuelve a casa,/por el camino natural. (BOGADO, 2014, p. 42) ${ }^{12}$.

Estes versos apontam uma denúncia diante da destruição da natureza, o que traz consequências irreversíveis para a vida, num sentido amplo, e contrastam com a cosmovisão presente no conceito de Teko Porã apresentado no lirismo dos versos da obra Ayvu i. Outro aspecto a ser levado em consideração é que a obra Ayvu $i$ está em edição bilíngue, sendo auto traduzida por Bogado, isto é, a auto tradução pode ser considerada a coincidência entre a instância do escritor e do tradutor (PEÑALVER, 2011, p. 195), ao passo que Cantos de la tierra está em castelhano, o que

\footnotetext{
10 "A inerte vida da terra/ vai se cubrindo de tempo/ e as rugas vão/ curtindo sua pele/ com um sem fim de sulcos/ invisíveis" (BOGADO, 2014, p. 42, tradução nossa).

11 "Hoje teus filhos legítimos,/ já estão morrendo contigo,/ e são teus outros filhos,/ os que vão deixando a/ herança de um triste/destino" (BOGADO, 2014, p. 42, tradução nossa).

12 "Em cada espaço de ar não-puro/é a humanidade que agoniza,/é ela mesma no/suicídio,/que se vai negando a vida./ Agoniza a terra,/agoniza inerte,/ mas é ela a vida/e mais tempo se sulcam/suas feridas./ Talvez o filho/ se detenha a pensar,/e a mãe agonizante,/ volte a se recuperar,/mas só o filho/volta para casa,/pelo caminho natural" (BOGADO, 2014, p. 42, tradução nossa).
} 
reforça as diferentes perspectivas de ambas. Por um lado, temos uma obra escrita em guarani, com sua respectiva auto tradução ao castelhano e, portanto, mais próxima a esta visão mítica e sagrada e, por outro lado, uma outra obra escrita apenas em castelhano e com um tom de denúncia frente aos efeitos de destruição da vida. É interessante que o autor encontra para a auto tradução de um mesmo vocábulo inúmeras possibilidades, dependendo da sonoridade, do sentido ou da falta de termo equivalente para traduzir a língua guarani, em sua variante Mbya, ao castelhano, o que revela, na tradução, um elemento ora em excesso ora em falta e que abre campo para a discussão da possibilidade do traduzir, mas também de sua impossibilidade como elemento constitutivo do sentido que não se resgata no movimento de traduzir.

A poesia do autor, portanto, coloca que o Teko Porã pode se constituir em ruptura frente ao discurso pós-colonial de progresso e desenvolvimento que acomete o Ocidente desde o período colonial e transformou todos os seres humanos e os recursos naturais em passíveis de exploração e até extinção, promovendo a ascensão dos setores dominantes e a pobreza e desigualdade social em ampla escala. Este discurso da colonialidade do ser, saber e poder cobriu-se das teorias racistas científicas para respaldar a dominação e a exclusão dos povos subjugados na América Latina, como aponta o crítico Aníbal Quijano (2000). Então, nesta perspectiva de mentalidade colonial imposta, o racismo e o preconceito fizeram parte da ideologia que justificou o domínio e a exploração de outros seres humanos e dos recursos naturais sob o jugo do poder colonial. A partir de alguns termos como "tensão no Oeste", o discurso jornalístico reforça um tom apocalíptico e espetacularizado que não coincide em parte com o conteúdo da notícia. Apesar de relacionar várias matérias sobre a questão do conflito de terra e da tentativa de retomada dos guaranis, estas tocam de modo lacônico em vários aspectos centrais da cosmovisão indígena. Já a poesia de Bogado investe num mergulho às profundezas e belezas de uma cultura viva, mas que não oblitera o tom de denúncia da destruição e degradação da natureza e da cultura a que a sociedade do Capital está subjugada pelos interesses de suas elites depredadoras.

\section{Considerações finais}

A poesia de Brígido Bogado, escrita em guarani e auto traduzida ao castelhano pelo próprio autor, num processo de criação e tradução, revela-nos esta cosmovisão de seu povo Mbya Guarani por meio da relação com a palavra encarnada de vida e espiritualidade. Neste sentido, temos a relação explicitada em sua poesia entre o ser guarani, estar na terra guarani e ainda poder falar a partir desta dimensão sagrada. Os estudos ecocríticos resgatam uma possibilidade de leitura interrelacional entre ser humano e demais seres da natureza, de modo a enfatizar estas relações irmanadas dos povos nativos com a territorialidade, numa concepção sagrada e mítica. A ecocrítica traz ainda elementos para contrastar esta narrativa do Teko Porã e sua cosmovisão constitutiva com a análise da notícia de jornal e o tom secular e espetacular que apresentam os conflitos que envolvem os guaranis. Isto ocorre por meio do choque entre concepções diametralmente opostas sobre o modo de entender e viver a territorialidade, de um lado, temos o caráter de ancestralidade e reverência dos povos nativos aos elementos da natureza e da humanidade e, por outro, a visão hegemônica do capital, da apropriação da terra e seu usufruto, numa concepção implantada desde a colonialidade do saber e poder na América Latina.

A língua guarani evidencia esta relação entre a cultura e os seres humanos ou não, sem hierarquias. Além disto, a auto tradução que o autor empreende e os desafios ao encontrar equivalências para um mesmo vocábulo mostram a busca pela possibilidade de traduzir e revelam que este ato comporta um elemento que produz excesso ou falta na língua de chegada, o que 
pode ser interpretado como a impossibilidade de traduzir as línguas e as culturas sem a perda de elementos. No caso da análise das notícias veiculadas, encontramos elementos próprios dos discursos jornalísticos que exploram o sensacionalismo e a espetacularização dos fatos, apesar de a matéria na íntegra, e seus links relacionados, conterem informações centrais e valiosas para o entendimento dos conflitos atuais e passados com relação à territorialidade e à identidade dos guaranis na região do Oeste do Paraná.

Este estudo deixa aberta ainda a necessidade de futuros trabalhos que visem ao aprofundamento desta possibilidade de uma perspectiva reflexiva da ecocrítica latino-americana e que promovam uma discussão destas formas de se relacionar com o espaço, tal qual a que apresentamos neste estudo. Acreditamos que há respostas em termos locais aos conflitos gerados por cosmovisões distintas entre os povos nativos e o Capital. Estes conflitos geram racismo ambiental, preconceito e lutas pela sobrevivência de povos e de culturas, as quais devem servir de caminho para a busca de alternativas de convivência harmônica entre os grupos e para a proposta de formas de reparação das desigualdades no acesso aos recursos e na relação entre os seres humanos e a natureza.

\section{Referências}

ALTAMIRANO, Lurdes. El primer poeta indígena de Paraguay Brígido Bogado presenta nuevo libro. Revistapy.com, Encarnación, 19 fev. 2019. Disponível em: <https://www.revistapy.com/?p=1403>. Acesso em: 30 out. 2019.

DIEGUES, Douglas. Entrevista com Douglas Diegues. Digestivo Cultural [Entrevista cedida a Julio Daio Borges], São Paulo, 01 jan. 2009. Disponível em: <http://www.digestivocultural.com/entrevistas/ entrevista.aspcodigo=28\&titulo=Douglas_Diegues $>$. Acesso em: 17 mai. 2018.

BOGADO, Brígido. Ayvu i. Asunción: Arandurã Editorial, 2009.

BOGADO, Brígido. Cantos de la tierra. Reflexiones poéticas de un Mbya Guaraní. Asunción: Fondec; Arandurã Editorial, 2014.

CADOGÁN, León. Ayvu Rapyta: Textos míticos de los Mbyá Guaraní del Guairá. Revista de Antropología, São Paulo, v. 1, n. 5, boletim n. 227, 1959. Disponível em: <http://etnolinguistica.wdfiles. com/local-files/biblio\%3Acadogan-1959-ayvu/Cadogan_1959_AyvuRapyta.pdf>. Acesso em: 06 mai. 2020 .

FLORES, William. Deconstrucciones teoréticas, desmitificación y voces indígenas: hacia uma ecocrítica latinoamericana. Revista International d'Humanitat, Barcelona, v. 39, p. 43-48, jan./abr. 2017. Disponível em: <http://www.hottopos.com/rih39/43-48Flores.pdf>. Acesso em: 30 abr. 2020.

MELIÁ, Bartolomeu. El buen vivir se aprende. Sinéctica, Tlaquepaque, v. 45, p. 1-12, jul./dez. 2015. Disponível em: <http://www.scielo.org.mx/pdf/sine/n45/n45a10.pdf>. Acesso em: 26 mai. 2017.

PARO, Denise. Guaranis vivem sob tensão no Oeste. H2FOZ, Foz do Iguaçu, 19 abril 2018. Disponível em: <https://www.h2foz.com.br/noticia/guaranis-vivem-sob-tensao-no-oeste>. Acesso em: 25 mai. 2018.

PEÑALVER, María Recuenco. Más allá de la traducción: la autotraducción. TRANS Revista de Traductología, Ciudad del Cabo, n. 15, p. 193-208, 2011. Disponível em: <http://www.trans.uma.es/ pdf/Trans_15/193-208.pdf>. Acesso em: 19 fev. 2020. 
QUIJANO, Aníbal. Colonialidad del poder: eurocentrismo y América Latina. In: LANDER, Edgardo (ed.). La colonialidad del saber: eurocentrismo y ciencias sociales. Perspectivas Latinoamericanas. Buenos Aires: CLACSO, 2000, p. 201-249.

RODAS, José Javier; BENÍTEZ, Carlos. Primer Diccionario Mbya Ayvu-Español/ Español-Mbyá Guaraní. Posadas: Editorial Universitaria de la Universidad Nacional de Misiones, 2018, 424 p. 